\title{
A profile of cases of gestational trophoblastic neoplasia at a tertiary care centre in South India
}

\author{
Rakesh M. P.*, Kalaichelvi K., Govind Gangadharan, Vishnu Sreedath
}

Department of Medical Oncology, Madras Medical College, Chennai, Tamil Nadu, India

Received: 09 April 2020

Accepted: 17 April 2020

\section{*Correspondence:}

Dr. Rakesh M. P.,

E-mail: mprakeshmp@gmail.com

Copyright: () the author(s), publisher and licensee Medip Academy. This is an open-access article distributed under the terms of the Creative Commons Attribution Non-Commercial License, which permits unrestricted non-commercial use, distribution, and reproduction in any medium, provided the original work is properly cited.

\begin{abstract}
Background: Gestational trophoblastic disease (GTD) comprises a spectrum of diseases ranging from molar pregnancy to malignant gestational trophoblastic neoplasia (GTN). GTN are highly chemo-sensitive tumours which are treated as per FIGO risk stratification. The rarity of the disease limits the evidence regarding the disease to case series and reports. The objective of this study was to study incidence, baseline characteristics of patients and clinical outcome of GTN patients treated at this centre.

Methods: This is a retrospective descriptive study based on medical records of patients of GTD who were registered in department of medical oncology, from January 2015 to December 2018 (4 years). GTN was diagnosed based on serum beta HCG values. Their baseline characteristics, risk score, serum $\beta$ HCG levels, and treatment regimens were investigated. The incidence of GTD and response to treatment were analysed.

Results: Out of 211 GTD patients, 56 developed GTN. The incidence was 3.4 per 10000 deliveries. Low risk cases $(\mathrm{n}=38)$ were treated with methotrexate and actinomycin in first line while high risk cases received EMACO and EP followed by EMACO as the first line. A cure rate of $100 \%$ for low risk cases and $94.4 \%(n=17)$ for high risk cases were recorded. Resistance to MTX was $32.3 \%$ while EMACO was resistant in $46.6 \%$ as first line. Neutropenia and alopecia were the most common treatment related adverse events. Predictors of resistance to single agent in low risk GTN include higher pre-treatment $\beta \mathrm{HCG}$ values and higher risk scores.

Conclusions: GTN exemplifies a rare, highly aggressive but curable malignancy. Serum $\beta H C G$ is the most reliable diagnostic as well as prognostic marker in management of GTD. EMACO is the preferred regimen for high risk GTN. FIGO staging and risk stratification help in individualizing the treatment to ensure maximum response to therapy thus making GTN a curable malignancy.
\end{abstract}

Keywords: Choriocarcinoma, EMACO, FIGO, Gestational trophoblastic neoplasia, Gestational trophoblastic disease, $\beta \mathrm{HCG}$

\section{INTRODUCTION}

Gestational trophoblastic disease (GTD) is comprised of a range of pregnancy related disorders, from premalignant hydatiform mole (complete and partial), to the malignant invasive mole, choriocarcinoma, placental site trophoblastic tumours and epithelioid tumour. ${ }^{1}$ The malignant ones are collectively called gestational trophoblastic neoplasia (GTN). The reported incidence of GTD varies from 23 per 100,000 (Paraguay) to 1,299 per
100,000 (Indonesia), though the incidence In India is inconsistent and variable. ${ }^{2}$ They usually follow a molar pregnancy though they can occur after any gestational event. The primary clinical concern regarding GTD is the risk of persistence in the uterus and elsewhere. Serum beta human chorionic Gonadotropin $(\beta \mathrm{HCG})$ is a sensitive marker in diagnosing and evaluating treatment response of GTN. ${ }^{3,4}$ The majority of women with this disease will be cured by single agent chemotherapy while high risk cases warrant the use of combination regimens. 
GTN is highly chemo sensitive with cure rates up to $100 \%$ for low risk disease and $80-90 \%$ in high risk cases. ${ }^{5}$

The aim of this retrospective study was to assess the management outcome of GTD treated at this institute from January 2015 to December 2018 (4 years).

\section{METHODS}

This study was conducted in the department of medical oncology. This is a retrospective descriptive study based on medical records and included all patients of GTD who were registered, diagnosed and treated in department of medical oncology, from January 2015 to December 2018 (4 years). The missing data was completed by looking at outpatient clinic records and by phone conversations. Patients diagnosed and treated elsewhere were excluded. Patients diagnosed elsewhere and treated here were also excluded. The baseline characteristics including age, parity, clinical symptoms, physical examination findings, X-ray, ultrasonogram were available for all patients. Baseline beta HCG was available for all patients. GTN was diagnosed based on serum beta HCG values and risk stratification was done as per FIGO staging 2002 and WHO scoring system. ${ }^{6,7}$ Low risk cases (score $\leq 6$ ) were given single agent chemotherapy (weekly methotrexate $50 \mathrm{mg} / \mathrm{m}^{2}$, Biweekly ACT-D $1.25 \mathrm{mg} / \mathrm{m}^{2}$, MTX $1 \mathrm{mg} / \mathrm{kg}$ IM alternating with Leucovorin $15 \mathrm{mg}$ per orally) while multiagent treatment was given for high-risk cases (score $\geq 7$ ). Patients were advised contraception and monthly follow up with $\beta \mathrm{HCG}$ for a period of one year once $\beta$ HCG normalizes after treatment for low risk and for 2 years for high risk disease. In a first. Authors described the patients' characteristics using traditional descriptive statistics: continuous variables were summarized using means, medians and standard deviation. Categorical variables were summarized mainly by proportions and percentages.

\section{RESULTS}

Out of 61,627 deliveries registered in the hospital during the study period, 211 patients of GTD were registered in the department of medical oncology during the same period. The incidence of GTD was 3.4 per 1000 deliveries. Majority of the patients belonged to 20-40 years age group $(n=187)(88.6 \%)$, with the mean age 23.8 years.

Baseline serum $\beta \mathrm{HCG}$ was documented in all cases.

Suction and evacuation were the preliminary procedure carried out in all patients, however 2 patients had to undergo hysterectomy for uncontrolled bleeding

A diagnosis of GTN was made in 56 patients (26.5\%). 38 patients $(18 \%)$ belonged to low risk GTN while 18 were high risk cases as per FIGO stage 2002.
Table 1: Baseline characteristics.

\begin{tabular}{|c|c|c|c|}
\hline \multicolumn{2}{|c|}{ Base line characteristics } & $\begin{array}{l}\text { No. of } \\
\text { patients }\end{array}$ & $\%$ \\
\hline \multirow{3}{*}{ Age } & $<20$ & 23 & $10.9 \%$ \\
\hline & $20-40$ & 187 & $88.6 \%$ \\
\hline & $>40$ & 1 & $0.5 \%$ \\
\hline \multirow{5}{*}{$\begin{array}{l}\text { No. of } \\
\text { children }\end{array}$} & Primi & 132 & $62.6 \%$ \\
\hline & Para 1 & 56 & $26.5 \%$ \\
\hline & Para 2 & 19 & $9.0 \%$ \\
\hline & Para 3 & 2 & $0.9 \%$ \\
\hline & Para 4 & 2 & $0.9 \%$ \\
\hline \multirow{4}{*}{$\begin{array}{l}\text { Type of } \\
\text { pregnancy }\end{array}$} & Mole & 194 & $92.4 \%$ \\
\hline & Term & 1 & $0.5 \%$ \\
\hline & Ectopic & 1 & $0.5 \%$ \\
\hline & $\begin{array}{l}\text { 1st trimester } \\
\text { abortion }\end{array}$ & 14 & $6.7 \%$ \\
\hline \multirow{6}{*}{$\begin{array}{l}\text { Presenting } \\
\text { complaint }\end{array}$} & $\begin{array}{l}\text { routine } 1^{\text {st }} \\
\text { trimester USG }\end{array}$ & 121 & $57.3 \%$ \\
\hline & Bleeding & 72 & $34.1 \%$ \\
\hline & Vomiting & 9 & $4.3 \%$ \\
\hline & Abdominal pain & 7 & $3.3 \%$ \\
\hline & Post delivery & 1 & $0.5 \%$ \\
\hline & $\begin{array}{l}\text { Neurological } \\
\text { deficit }\end{array}$ & 1 & $0.5 \%$ \\
\hline \multirow{3}{*}{$\begin{array}{l}\text { Uterine size } \\
\text { USG }\end{array}$} & $<10 \mathrm{w}$ & 30 & $14.2 \%$ \\
\hline & $10-16 \mathrm{w}$ & 168 & $79.6 \%$ \\
\hline & $>16$ & 13 & $6.2 \%$ \\
\hline \multirow{3}{*}{ Tl cyst } & Absent & 191 & $91.0 \%$ \\
\hline & Unilateral & 8 & $3.8 \%$ \\
\hline & Bilateral & 11 & $5.2 \%$ \\
\hline \multirow{7}{*}{$\begin{array}{l}\text { Other USG } \\
\text { findings }\end{array}$} & Invasive mole & 4 & $1.9 \%$ \\
\hline & $\begin{array}{l}\text { Suburethral } \\
\text { nodule }\end{array}$ & 1 & $0.5 \%$ \\
\hline & Blighted ovum & 1 & $0.5 \%$ \\
\hline & Vaginal mass & 1 & $0.5 \%$ \\
\hline & $\begin{array}{l}\text { Uterine artery } \\
\text { AVM }\end{array}$ & 1 & $0.5 \%$ \\
\hline & $\begin{array}{l}\text { Vesicular } \\
\text { mole }\end{array}$ & 1 & $0.5 \%$ \\
\hline & $\begin{array}{l}\text { Pregnancy } \\
\text { with vesicular } \\
\text { mole }\end{array}$ & 2 & $0.9 \%$ \\
\hline
\end{tabular}

Table: 2: Serum $\beta$ HCG levels.

\begin{tabular}{|lll|}
\hline HCG $(\mathrm{mIU} / \mathrm{ml})$ & (Pre-evacuation) & \\
\hline & No. of patients & $\%$ \\
\hline$<1000$ & 5 & $2.4 \%$ \\
\hline $1000-10000$ & 20 & $9.5 \%$ \\
\hline $10000-100000$ & 58 & $27.5 \%$ \\
\hline Above 100000 & 128 & $60.7 \%$ \\
\hline
\end{tabular}

Single agent methotrexate weekly was given for 32 patients while 4 patients received actinomycin-d and 2 patients methotrexate with leucovorin (Figure 1). 
Table: 3: Procedures undergone.

\begin{tabular}{|ll|}
\hline Procedure undergone & No. of patients \\
\hline S and E & 206 \\
\hline TAH & 2 \\
\hline Normal delivery & 2 \\
\hline MTP & 1 \\
\hline
\end{tabular}

Table 4: Histopathology and risk score.

\begin{tabular}{|llll|}
\hline \multirow{5}{*}{ Histopathology } & & No. & $\%$ \\
\cline { 2 - 4 } & Not available & 8 & $3.8 \%$ \\
\cline { 2 - 4 } & Partial mole & 39 & $18.5 \%$ \\
\cline { 2 - 4 } & Complete mole & 158 & $74.9 \%$ \\
\hline \multirow{2}{*}{ Risk score } & Choriocarcinoma & 6 & $2.8 \%$ \\
\cline { 2 - 4 } & $0-6$ & 38 & $67.8 \%$ \\
\hline
\end{tabular}

Table 5: FIGO stage.

\begin{tabular}{|llll|}
\hline \multirow{5}{*}{ Figo stage } & Stage & No. & $\%$ \\
\cline { 2 - 4 } & Stage 1 & 47 & $84 \%$ \\
\cline { 2 - 4 } & Stage 2 & 0 & $0.0 \%$ \\
\cline { 2 - 4 } & Stage 3 & 5 & $8.9 \%$ \\
\cline { 2 - 4 } & Stage 4 & 4 & $7.1 \%$ \\
\hline
\end{tabular}

Table 6: Pre-treatment $\beta$ HCG values.

\begin{tabular}{|llll|}
\hline & Stage & No. & $\%$ \\
\hline \multirow{3}{*}{$\begin{array}{l}\text { Pre-treatment } \\
\beta \text { HCG }\end{array}(\mathrm{mIU} / \mathrm{ml})$} & $<1000$ & 6 & $2.8 \%$ \\
\cline { 2 - 4 } & $1000-10000$ & 18 & $8.5 \%$ \\
\cline { 2 - 4 } & $10000-100000$ & 22 & $10.4 \%$ \\
\cline { 2 - 4 } & Above 100000 & 10 & $4.7 \%$ \\
\hline
\end{tabular}

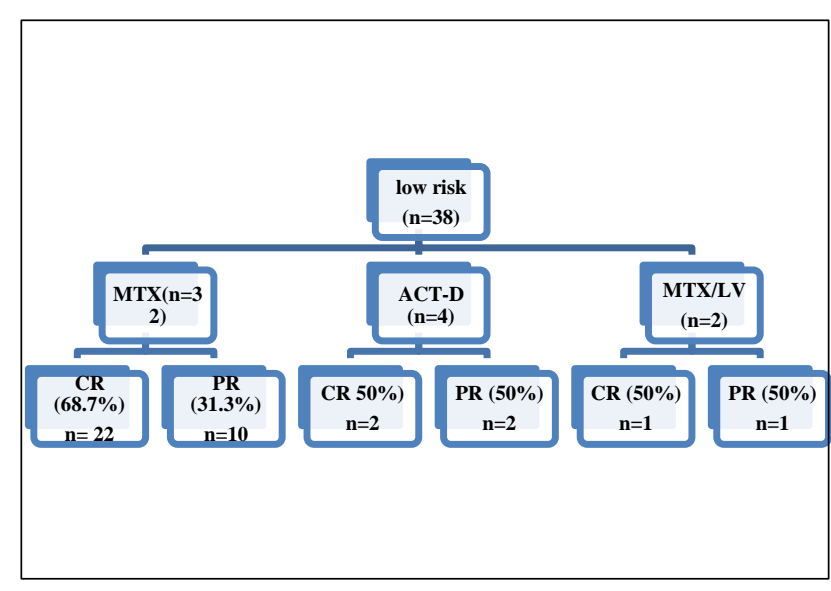

Figure 1: $1^{\text {st }}$ line treatment algorithm for low risk.

Complete response was achieved in 25 patients with $1^{\text {st }}$ line while 12 patients went on to receive $2^{\text {nd }}$ line treatment, 1 patient to 3 rd line and 1 patient defaulted. (Figure 2).

Weekly methotrexate $\left(50 \mathrm{mg} / \mathrm{m}^{2}\right)$ produced a complete response in $68 \%$ of patients as first line therapy and a complete response was seen in all low-risk patients at the end of treatment.

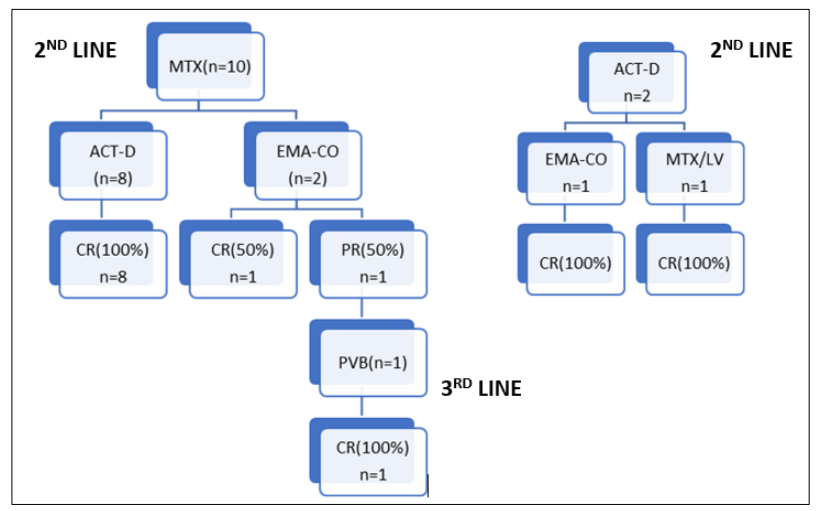

Figure 2: Treatment algorithms for low risk resistant cases.

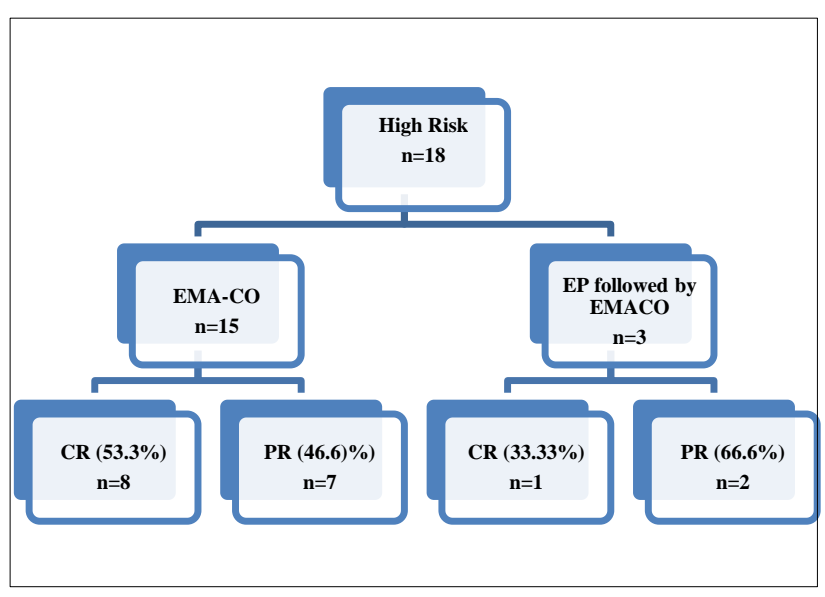

Figure 3: Treatment algorithm for high risk cases.

Multiagent chemotherapy was given to all patients as per the institution protocol and ECOG performance status of the patient for high risk patients. The maximum score calculated was 20. Fifteen patients received EMA-CO, while 3 patients received weekly etoposide and cisplatin followed by EMACO (Figure 3).

Complete response was achieved in $9(50 \%)$ after 1 st line while 9 patients went on to receive salvage chemotherapy (Figure 3). various salvage regimes include PVB, BEP, VIP, ICE. Two patients received high dose methotrexate (HD-MTX) in their $4^{\text {th }}$ line. The patient with a score of 20 received 5 lines of salvage therapy. One patient with heavy vaginal bleeding had uterine AV malformation which is a rare association of trophoblastic disease and was managed with uterine artery embolization. A complete response was seen in 17 patients $(94.4 \%)$ at the end of treatment involving multiple lines while 1 patient succumbed to illness.

Neutropenia and alopecia were the most common treatment related adverse events. No grade 3 , grade 4 adverse events were noted. Three patients had coexisting 
hyperthyroidism. Twenty-nine GTN patients successfully completed 12 months of follow up after treatment. All were on oral contraceptive pills.

\section{DISCUSSION}

GTN includes a group of tumors which constitute less than $1 \%$ of gynecological malignancies. They are extremely chemo sensitive and hence chemotherapy is the main modality of treatment even in metastatic setting and the overall cure rate is around 90-100\%. ${ }^{4}$ The management of GTN depends on the FIGO staging, risk stratification and performance status of the patient. With the advent of ultrasonogram-Doppler and sensitive beta HCG assays, diagnosis of GTD has become possible even before the patient is symptomatic as seen in this study where the majority of patients $(57.3 \%)$ were diagnosed to have molar pregnancy on routine first trimester ultrasound scanning (Table 1).

The incidence of molar pregnancy varies from places to places as any other disease. Literature suggest its incidence in USA as 1 in 1500, while in UK- 1-3 in 1000 and 2 in 1000 in South East Asia. ${ }^{8,9}$ In this study the incidence was 3.4 per 1000 deliveries as the centre being a tertiary referral centre with facilities dedicated for GTD management (211 in 61627 deliveries). Data from a similar study from North India show an incidence of 2.3 per 1000 deliveries. ${ }^{10}$ Choriocarcinoma has a varied incidence worldwide. In south east Asia the incidence is 9.2 in 40000 pregnancies. $^{11}$

Advanced maternal age is considered as one of the risk factors for GTN. ${ }^{12} 187(88.6 \%)$ patients in this study belonged to $20-40$ age group and only 23 patients were less than 20 years (Table 1). However, in this study all the low risk and high risk GTN patients were below 40 years of age. The mean age of GTD in similar studies carried out in India were 23.02 years and 24.6 years. ${ }^{13}$ Most of these patients were primi para. It is not uncommon to have theca lutein (TL) cysts in GTD. TL cysts was seen in $9 \%$ of GTD patients in this study (Table 1). The average uterine size was between 10-16 weeks $(79.6 \%)$ and 13 patients had uterine size greater than the gestational age (Table 1). Hyperthyroidism without features of thyroid storm was seen in 3 patients however a definite correlation between beta HCG levels and Hyperthyroidism could not be made. Histopathological analysis after suction and evacuation showed complete mole in 158 patients $(74.9 \%)$ while partial mole was seen in $39(18.4 \%)$ patients (Table 4$)$.

Low risk patients, $(n=38)$ were started on single agent chemotherapy (Figure 1). Intermediate risk patients (score 4-6) were also given single agent chemotherapy to begin with. Majority of patients received low dose MTX $\left(50 \mathrm{mg} / \mathrm{m}^{2}\right)$ in fist line treatment as shown in Figure 1. Complete remission (CR) was seen in $65.8 \%$ of patients following first line treatment. ${ }^{13}$ patients received $2^{\text {nd }}$ line treatment (Figure 2). A $100 \%$ CR was achieved for the entire low risk group at the end of the treatment. Resistance to first line regimen is seen in $45-50 \%$ of low risk GTN. ${ }^{14-16}$ Resistance to weekly methotrexate in this study is $31.3 \%$, while literature shows a resistance of 20$26 \% .^{5,17,18}$ Probable causes may be FIGO score 5-6 and $\beta \mathrm{HCG}>10,000 .{ }^{16}$ In spite of chemoresistance, with the use of multi agent chemotherapy, the salvage rate in low risk GTN is $100 \%$, as seen in this study (Figure 2). ${ }^{16,19}$

Patients with high risk GTN (score >6) are likely to develop drug resistance if single agent therapy is administered. As per an early work at National Cancer Institute, only $36 \%$ of high-risk patients achieved remission with single agent. ${ }^{20}$ Out of 18 patients, EMACO (etoposide, methotrexate, actinomycin, cyclophosphamide, vincristine) was given for 15 patients. (Figure 3). 3 patients who had poor performance status and very high-risk score, received induction with low dose etoposide followed by EMACO once general condition improved (Figure 3). A complete response was seen in 9 patients $(50 \%)$. (Figure 3 ). The patient with score 20 , received 5 lines of salvage, paclitaxel/5FU being the $5^{\text {th }}$ line especially when the $\beta$ HCG was plateauing at a low level $(10 \mathrm{mIU} / \mathrm{ml})$. The remission rate with EMACO in this study was $53.3 \%$. The studies by Alzzam et al, and Goldstein et al, suggest that $30 \%$ to $40 \%$ of high risk GTN develop resistance to EMACO. ${ }^{14,21}$ It is in concurrence with the result of $46.6 \%$ resistance seen in this study. However, the choice of salvage was treating physician's discretion depending on the ECOG performance status and availability of drugs, in low resource settings. Four patients with score more than 10 had received at least 3 lines of salvage therapy, Patients with brain metastasis $(\mathrm{n}=3)$ received HD-MTX $\left(1 \mathrm{~g} / \mathrm{m}^{2}\right)$. No grade 3-4 toxicities were documented during the treatment. All regimens were well tolerated. A cure rate of $94.4 \%(n=17)$ was achieved in high risk patients with multiple lines of salvage therapy even though the studies say only $80 \%$ to $90 \%$ cure. $^{22,23}$ A single mortality was recorded which was secondary to CNS metastasis. A close and meticulous follow up is mandatory for early detection of resistance and relapse. Only 50\% ( $n=29)$ of GTN patients completed a follow up of 12 months which is the major challenge faced by the treating physician as $85-95 \%$ of recurrences occur in first 18 months. $^{24}$ However, the sensitivity of $\beta \mathrm{HCG}$ has made it possible for the early detection and prompt intervention in case of resistance.

\section{CONCLUSION}

GTN exemplifies a rare, highly aggressive but curable malignancy. Serum $\beta \mathrm{HCG}$ is the most reliable diagnostic as well as prognostic marker in management of GTD. Early detection of resistance is feasible with serial $\beta \mathrm{HCG}$ monitoring. Low risk GTN usually responds to single agent chemotherapy while high Risk warrants the use of multi agent therapy. Single agent methotrexate is still the preferred regimen in this institute for low risk patients, though studies show higher CR rates with Act-D as the 
first line treatment. Predictors of resistance to single agent in low risk GTN include non-molar antecedent pregnancy, higher pre-treatment $\beta \mathrm{HCG}$ values and higher risk scores. EMACO is the preferred regimen for high risk GTN with primary remission rates ranging from $54 \%$ to $91 \%$. Patient compliance is of utmost importance in treatment and follow up of GTN. Patients should be educated about the need for contraception following completion of treatment. Serum $\beta \mathrm{HCG}$ assay, FIGO staging and risk stratification help in individualizing the treatment to ensure maximum response to therapy thus making GTN a curable malignancy

Funding: No funding sources Conflict of interest: None declared

Ethical approval: The study was approved by the Institutional Ethics Committee

\section{REFERENCES}

1. Seckl MJ, Sebire NJ, Berkowitz RS. Gestational trophoblastic disease. Lancet. 2010;376(9742):71729.

2. Altieri A, Franceschi S, Ferlay J, Smith J, La Vecchia C. Epidemiology and aetiology of gestational trophoblastic diseases. Lancet Oncol. 2003;4(11):670-8.

3. Aminimoghaddam S, Yarandi F, Nejadsalami F, Taftachi F, Noor Bakhsh F, Mahmoudzadeh F. Human chorionic gonadotrophin as an indicator of persistent gestational trophoblastic neoplasia. Med J Islam Repub Iran. 2014;28:44.

4. Berkowitz RS, Goldstein DP. Chorionic Tumors. N Engl J Med. 1996;335(23):1740-8.

5. Homesley HD. Single-agent therapy for nonmetastatic and low-risk gestational trophoblastic disease. J Reprod Med. 1998;43(1):69-74.

6. PDQ Adult Treatment Editorial Board PATE. Gestational Trophoblastic Disease Treatment (PDQ®): Health Professional Version. PDQ Cancer Information Summaries. National Cancer Institute (US); 2002. Available at: http://www.ncbi.nlm.nih.gov/pubmed/26389414. Accessed on $10^{\text {th }}$ June 2019.

7. FIGO Committee on Gynecologic Oncology. Current FIGO staging for cancer of the vagina, fallopian tube, ovary, and gestational trophoblastic neoplasia. Int J Gynaecol Obstet. 2009;105(1):3-4.

8. Loukovaara M, Pukkala E, Lehtovirta P, Leminen A. Epidemiology of hydatidiform mole in Finland, 1975 to 2001. Eur J Gynaecol Oncol. 2005;26(2):207-8.

9. Garner EIO, Goldstein DP, Feltmate CM, Berkowitz RS. Gestational trophoblastic disease. Clin Obstet Gynecol. 2007;50(1):112-2.

10. Lakra P, Sangwan V, Siwach S, Kansal R, Mahendru $\mathrm{R}$, Sharma A. Outcome of gestational trophoblastic disease in a rural tertiary centre of Haryana, India. Int J Reprod Contraception, Obstet Gynecol. 2016;6(1):271.
11. Lurain JR. Gestational trophoblastic disease I: epidemiology, pathology, clinical presentation and diagnosis of gestational trophoblastic disease, and management of hydatidiform mole. Am J Obstet Gynecol. 2010;203(6):531.

12. Horowitz NS, Goldstein DP, Berkowitz RS. Management of gestational trophoblastic neoplasia. Semin Oncol. 2009;36(2):181-9.

13. Shrivastava S, Kataki A, Deka P, Bhuyan C, Barmon D, Bhargav S. Gestational trophoblastic neoplasia: A 6-year retrospective study. South Asian J Cancer. 2014;3(1):33.

14. Alazzam M, Tidy J, Osborne R, Coleman R, Hancock BW, Lawrie TA. Chemotherapy for resistant or recurrent gestational trophoblastic neoplasia. In: Alazzam M, editor. Cochrane Database of Systematic Reviews. Chichester, UK: John Wiley and Sons, Ltd; 2012:CD008891.

15. Alazzam M, Tidy J, Bw H, Osborne R, Ta L. Firstline chemotherapy in low-risk gestational trophoblastic neoplasia. Review. 2014;7.

16. Mousavi AS, Zamani A, Khorasanizadeh F, Gilani MM, Zendehdel K. Resistance to single-agent chemotherapy and its risk factors in low-risk gestational trophoblastic neoplasms. J Obstet Gynaecol Res. 201;41(5):776-83.

17. Homesley HD, Blessing JA, Schlaerth J, Rettenmaier M, Major FJ. Rapid escalation of weekly intramuscular methotrexate for nonmetastatic gestational trophoblastic disease: a gynecologic oncology group study. Gynecol Oncol. 1990;39(3):305-8.

18. Homesley HD, Blessing JA, Rettenmaier M, Capizzi RL, Major FJ, Twiggs LB. Weekly intramuscular methotrexate for nonmetastatic gestational trophoblastic disease. Obstet Gynecol. 1988;72(3 Pt 1):413-8.

19. Schink JC, III JRL. Gestational trophoblastic disease: Molar pregnancy and gestational trophoblastic neoplasia. Wolters Kluwer Health; 2013:886-908.

20. Ross GT, Goldstein DP, Hertz R, Lipsett MB, Odell WD. Sequential use of methotrexate and actinomycin $\mathrm{d}$ in the treatment of metastatic choriocarcinoma and related trophoblastic diseases in women. Am J Obstet Gynecol. 1965;93:223-9.

21. Goldstein DP, Berkowitz RS. Current management of gestational trophoblastic neoplasia. Hematol Oncol Clin North Am. 2012;26(1):111-31.

22. Khan F, Everard J, Ahmed S, Coleman RE, Aitken M, Hancock BW. Low-risk persistent gestational trophoblastic disease treated with low-dose methotrexate: efficacy, acute and long-term effects. Br J Cancer. 2003;89(12):2197-201.

23. McNeish IA, Strickland S, Holden L, Rustin GJS, Foskett M, Seckl MJ, et al. Low-risk persistent gestational trophoblastic disease: outcome after initial treatment with low-dose methotrexate and folinic acid from 1992 to 2000. J Clin Oncol. 2002;20(7):1838-44. 
24. Mutch DG, Soper JT, Babcock CJ, Clarke-Pearson DL, Hammond CB. Recurrent gestational trophoblastic disease. Experience of the southeastern regional trophoblastic disease center. Cancer. 1990;66(5):978-82.
Cite this article as: Rakesh MP, Kalaichelvi K, Gangadharan G, Sreedath V. A profile of cases of gestational trophoblastic neoplasia at a tertiary care centre in South India. Int J Reprod Contracept Obstet Gynecol 2020;9:1788-93. 